\title{
pro.posıções
}

$e$-ISSN 1980-6248

http://dx.doi.org/10.1590/1980-6248-2015-0155

ARTIGOS

\section{Professores (as) de enfermagem: gênero, trajetórias de trabalho e de formaçãa ${ }^{1}$}

\section{Teachers of nursing: gender, trajectories of work and of formation}

\section{Profesores (as) de enfermería: género, trayectorias de trabajo y formación}

Cristiane Batista Andrade (i)

Maria Inês Monteiro (ii)

(i) Fundação Oswaldo Cruz, Rio de Janeiro, RJ, Brasil. https://orcid.org/0000-0003-1441-9171, cristianeandrade@fiocruz.br

(ii) Universidade Estadual de Campinas - Unicamp, Campinas, SP, Brasil. https://orcid.org/0000-00026004-8378,inesmon@ unicamp.br

Resumo: Este texto analisa as trajetórias de formação e de trabalho de professores(as) enfermeiros(as) do ensino técnico de enfermagem, na dimensão das relações de gênero. A pesquisa, com referencial teórico e metodológico relativo à divisão sexual do trabalho e à história oral, entrevistou quatro professoras e dois professores do ensino técnico em enfermagem. O estudo revelou diferenças na forma como os homens e as mulheres iniciaram suas carreiras e no desenvolvimento de suas trajetórias profissionais, em função da interferência de aspectos familiares, como casamento e filhos. Constatou, no entanto, similitudes no trabalho de profissionais de ambos os gêneros quanto ao ato educativo: homens e mulheres se preocupam com a qualidade do processo de ensino e aprendizagem e fazem da educação um espaço de cuidado do outro.

Palavras-chave: relações de gênero, enfermagem, educação profissional, trabalho

\footnotetext{
1 Apoio: Coordenação de Aperfeiçoamento de Pessoal de Nível Superior - Capes.
} 


\section{pro.posıções}

$e$-ISSN 1980-6248

http://dx.doi.org/10.1590/1980-6248-2015-0155

Abstract: The aim of this research is to analyse the formation and work trajectories of technical nursing education teacher nurses, in the dimension of gender relations. With a theoretical and methodological framework related to the sexual division of labor and to oral history, the researchers interviewed four female and two male teachers. The study revealed differences in the way the male and the female teacher nurses began their careers, as well as in the developments of their professional trajectories, due to the interference of familial matters, such as marriage and children. On the other hand, similarities were observed in relation to the educational act: the men and the women are both concerned with the quality of the teaching and learning process and made education an area of caring for others.

Keywords: gender relationships, nursing, professional education, work

Resumen: Este texto analiza las trayectorias de formación, el trabajo de profesores(as) de enfermería de educación técnica y las relaciones de género. En la investigación, con el marco teórico y metodológico de la historia oral y de la división sexual del trabajo, se entrevistó cuatro profesoras $y$ dos profesores. El estudio reveló diferencias en la manera como los hombres y las mujeres empezaron sus carreras y en el desarrollo de sus trayectorias profesionales, en función de la interferencia de aspectos familiares, como casamiento e hijos. Constató, sin embargo, similitudes en el trabajo de ambos géneros en la acción educativa: hombres y mujeres se preocupan con la calidad de la enseñanza y del aprendizaje, y hacen de la educación un espacio de cuidado con el otro.

Palabras clave: relaciones de género, enfermería, educación profesional, trabajo

\section{Introdução}

É a partir de duas profissões predominantemente femininas - a enfermagem e a docência - que propomos analisar as trajetórias de formação e de trabalho de professoras e professores de um curso de nível técnico em enfermagem, sob a perspectiva das relações de gênero.

Se a construção social do cuidado e da educação tem como centralidade a participação predominantemente das mulheres, as relações de gênero estão postas como categoria de análise por compreender que o trabalho feminino é portador de baixos salários e de desigualdades nas trajetórias de mulheres, se comparado com o dos homens. Somam-se a isso as imbricações entre ser mulher e seus saberes utilizados no trabalho das esferas produtiva e reprodutiva (Bruschini \& Lombardi, 2002). 


\section{pro.posıções}

$e$-ISSN 1980-6248

http://dx.doi.org/10.1590/1980-6248-2015-0155

Em se tratando do estudo de gênero, o trabalho na perspectiva marxista traz como centralidade as relações entre o ser humano e seu envolvimento com a natureza e a sociedade capitalista. Se, por um lado, explicita o controle do capital, a mais-valia e as condições de trabalho, por outro, essa concepção não envolve o trabalho sexuado, diferenciado para os homens e as mulheres. Os estudos da divisão sexual do trabalho apontam as diferenciações entre ser trabalhador e trabalhadora, como é o caso das mulheres, que desempenham atividades não remuneradas, como o cuidado doméstico, dos filhos e da família. Portanto, as relações de gênero implicam na compreensão de que as mulheres desenvolvem atividades profissionais e domésticas, na esfera da produção e da reprodução e, muitas vezes, ganham menos que os homens (Bruschini \& Lombardi, 2002; Hirata \& Kergoat, 2009).

Ao colocarmos na centralidade o debate sobre trabalho de homens e mulheres e suas trajetórias, é possível pensar que as origens sociais, de classe, gênero e raça influenciam a formação profissional e também as condições de trabalho (Segnini, 2014). Elias (1995), ao estudar a vida e a trajetória de Mozart, nos dá pistas de que os desejos, os anseios e as vontades vão acontecendo na medida das experiências que os indivíduos vão adquirindo nas relações sociais: "Desde os primeiros anos de vida, os desejos vão evoluindo, através do convívio com outras pessoas, e vão sendo definidos, gradualmente, ao longo dos anos, na forma determinada do curso da vida" (p.13). Nesse sentido, as posições dos indivíduos na sociedade não deixam de ser construções sociais. O desejo de ser enfermeira ou professora é influenciado pelos papéis sociais das mulheres na sociedade.

A partir disso, dizemos que o cuidar é integrante do processo de trabalho da enfermagem, sendo desempenhado majoritariamente por mulheres ao longo do tempo. A história mostra as mulheres como realizadoras do trabalho de cuidado de pessoas doentes ou não, de crianças, idosos, adultos e jovens. Do ponto de vista do desenvolvimento da prática do cuidado, às mulheres coube o trabalho dito "feminino", no qual a minúcia, a delicadeza, a solicitude e a paciência são dadas como integrantes do trabalho de cuidar. Não sem razão, a enfermagem é tida como uma profissão de saberes femininos (Lopes \& Leal, 2005).

Se o cuidar é uma construção social, o ensino para o cuidado também o é (Waldow, 2009). O ensino de enfermagem, assim como o de outras áreas, teve contribuições das mulheres. Do ponto de vista histórico, a entrada delas no magistério significou o aumento da renda, a ruptura com os dogmas matrimoniais e com seu trabalho gratuito. O ensino foi tido como 


\section{pro.posições}

$e$-ISSN 1980-6248

http://dx.doi.org/10.1590/1980-6248-2015-0155

conquista no espaço público, em que os saberes femininos (a maternagem e os saberes domésticos) foram utilizados por elas para a inserção e a ascensão na carreira educacional (Almeida, 2006; Vianna, 2013).

A explicação dada para esse contingente de mulheres na área educacional é devida à "vocação" que esteve vinculada à expertise feminina, já que ensinar está relacionado com a continuidade do cuidado e, portanto, com a obrigação delas na sociedade patriarcal (Bruschini \& Amado, 1998). Os dados da Pesquisa Nacional por Amostra de Domić́lio (PNAD) de 2004 corroboram essa ideia - 78,2 dos profissionais da educação são mulheres (Andrade, 2015). Elas se concentram nos chamados guetos femininos, como as áreas de saúde, educação e arte, tendo em vista a qualificação para assumir empregos nesses setores (Bruschini \& Lombardi, 2002).

O estudo das relações de gênero na enfermagem perpassa a história do desenvolvimento da profissão. A entrada dos homens, sobretudo no final dos anos de 1960, influenciou as mudanças no cenário da enfermagem. A eles foram atribuídos cargos de chefia nos serviços de saúde e também nas instituições de classe. O uso do termo "enfermeiro", em lugar de "enfermeira", esteve relacionado com esse movimento, expressando que "a identidade profissional feminina foi transferida para o gênero masculino pelas próprias enfermeiras, como um tipo de renúncia à responsabilidade do desenvolvimento da profissão ou como se elas (nós) não soubessem o valor da identidade que possuem" (Padilha, Vaghetti, \& Brodersen, 2006, p. 298). Nesse momento, vemos a confirmação do poder masculino, a despeito da linguagem como relação de poder.

As atividades de cuidado que caracterizam o trabalho das enfermeiras passam pelo processo de profissionalização, com respaldo na legislação, exigindo-se, assim, a formação de nível superior. A história mostra que, em 1949, foi promulgada a lei que legislava sobre o ensino de enfermagem, caracterizado pelo curso de graduação e o de auxiliar. Entretanto, foi somente com a promulgação da Lei 4.024, pós-Lei de Diretrizes e Bases - LDB de 1961, que o curso passou a ser de nível superior, sendo o técnico de enfermagem criado em 1966: "o trabalho de enfermagem fica sendo desenvolvido por quatro categorias: atendente de enfermagem (a maioria sem ter passado por qualquer qualificação profissional), auxiliar de enfermagem, técnico de enfermagem e enfermeiro" (Pereira \& Ramos, 2006, p. 32). Ao técnico caberia auxiliar o enfermeiro no planejamento e na assistência aos clientes (Bassinello, 2007). 


\section{pro.posıções}

$e$-ISSN 1980-6248

http://dx.doi.org/10.1590/1980-6248-2015-0155

O trabalho de enfermagem tem como centralidade o cuidado (Waldow, 2009). Traz no seu fundamento o desprendimento de atividades de atenção, responsabilidade, solicitude e preocupação com o outro; o contato face a face, verbal e uma convivência maior, abarcando a dimensão psíquica, cognitiva e emocional. Está na interface com o encontro social entre as pessoas e os (as) trabalhadores (as) de enfermagem e nas relações entre os indivíduos. Uma atividade que mantém o contato direto com o corpo do outro, em que a expressão de amabilidade, gentileza, dissimulação, irritação e hostilidade são a centralidade das contradições no cuidar do outro, permeadas pelas diferenciações de gênero, geração, raça e classe social (Soares, 2012).

Sendo assim, esta pesquisa tem as seguintes questões norteadoras: de que maneira os (as) professores(as)/enfermeiros(as) constroem a carreira no ensino do cuidado? Há diferenciações e/ou similitudes nas suas trajetórias? Nesse sentido, tem como objetivo analisar as trajetórias de formação e de trabalho deles(as) no ensino técnico de enfermagem, indagandoas na dimensão das relações de gênero.

\section{Os caminhos da pesquisa}

A pesquisa foi desenvolvida por meio de entrevistas semiestruturadas, realizadas em outubro, novembro e dezembro de 2011, com dois professores e quatro professoras de um programa de formação de técnicos de enfermagem proposto pelo governo do estado de São Paulo, o TECSAÚDE. Foram enviadas cartas oficiais para a direção da escola que acolheria a pesquisa. Posteriormente, foi apresentada a proposta da pesquisa para o conjunto de professores. Após o aceite dos docentes e da direção da escola, foi elaborado um cronograma para as entrevistas, feitas no local de trabalho, em horários disponíveis dos professores. Todos autorizaram a gravação em meio digital. As entrevistas tiveram duração aproximada de uma hora e meia cada uma, foram gravadas em aparelho digital e posteriormente transcritas. Após esse procedimento, as pesquisadoras encaminharam a versão escrita para os entrevistados por endereço eletrônico. Nenhum deles quis complementar ou excluir parte do depoimento.

Com relação aos aspectos metodológicos, enfatiza-se a contribuição da história oral. É por meio dela que o objeto de pesquisa é analisado, pois os depoimentos permitem a 


\section{pro.posições}

$e$-ISSN 1980-6248

compreensão dos caminhos percorridos pelos professores e pelas professoras, suas diferentes trajetórias, seus desejos e anseios:

o oral nos revela o "indescritível", toda uma série de realidades que raramente aparecem nos documentos escritos, seja porque são consideradas "muito insignificantes"- é o mundo da cotidianidade - ou porque são impossíveis de transmitir pela escrita. [ênfase no original] É através do oral que se pode apreender com mais clareza as verdadeiras razões de uma decisão; que se descobre o valor das malhas tão eficientes quanto as estruturas oficialmente reconhecidas e visíveis; que se penetra no mundo do imaginário e do simbólico, que é tanto motor e criador da história quanto o universo racional. (Joutard, 2000, pp. 33-4)

Assim, as entrevistas proporcionaram o contato com os professores e a expressão de suas trajetórias profissionais e de formação, de sua entrada na carreira, seus conflitos, tensões e mobilizações diante das dificuldades no ensino, sua rotina e o cotidiano de trabalho na educação profissional. Depois de algumas entrevistas, foi preciso acrescentar algumas questões ao roteiro. Tal como aponta Demartini (1999), conforme as entrevistas vão acontecendo, algumas questões são passíveis de serem aprofundadas, pois a experiência da pesquisadora e os relatos dos sujeitos direcionam a melhoria do procedimento obtido na interação:

É um procedimento cumulativo, que resulta da escuta atenta, da reflexão sobre as informações que vão sendo coletadas e que implicam em novos questionamentos nas entrevistas subsequentes. Sem contar que nunca se sabe a priori "o que" vai ser contado em cada nova entrevista, nem "como" vai ser contado. (p.35)

O estudo das representações se fez presente, já que não somente são constitutivas de sociabilidades e da história de um grupo social, mas também permitem compreender como mulheres e homens constroem e formam as regras, os pensamentos, as emoções e interagem com o saber-fazer no trabalho, na sua qualificação profissional. A dinâmica do trabalho, pensada como relação social e historicamente construída (Kergoat, 1986), é compreendida por meio das representações elaboradas por esses (as) docentes ao longo do processo de formação e de trabalho.

O projeto foi aprovado pelo Comitê de Ética em Pesquisa da Faculdade de Ciências Médicas da Universidade Estadual de Campinas, e foi utilizado o termo de consentimento livre e esclarecido, sob o protocolo 069/2011 (CAAE- 0040.0.146.000-11). Para garantir o sigilo de suas identidades, foram substituídos os nomes: as professoras foram denominadas A1, A2, A3 e A4 e os professores, B1 e B2. 


\section{pro.posıções}

$e$-ISSN 1980-6248

http://dx.doi.org/10.1590/1980-6248-2015-0155

No ano de 2009 foram realizadas 42.322 matrículas no TECSAÚDE, no curso técnico em enfermagem no estado de São Paulo. Em Campinas, havia 2.268 alunos matriculados. Nesse mesmo ano, além da capital, 17 cidades do interior de São Paulo participaram da implementação do programa. Os polos de desenvolvimento do TECSAÚDE estão presentes em todo o estado, em unidades descentralizadas. Para isso, as escolas privadas ou públicas são submetidas aos editais de credenciamento, publicados através de editais oficiais (São Paulo, 2009).

A contratação dos sujeitos desta pesquisa teve início em fevereiro de 2011, sendo realizada por processo seletivo. A escola na qual foi feita a pesquisa selecionou professores por meio de banco de currículos, e eles foram convocados para realizar uma aula expositiva e uma entrevista com coordenadores do curso. Os professores possuíam vínculo empregatício pela Consolidação das Leis Trabalhistas (CLT), com carga horária de 20 horas, 25 horas ou 40 horas semanais. O tempo das atividades é gasto em sala de aula, reuniões pedagógicas, supervisão de estágios, elaboração de aulas, correção de provas, etc. Neste caso, parece ocorrer um avanço nas condições de trabalho dos professores, pois o salário não está associado apenas à quantidade de horas aula ministradas.

\section{As trajetórias de formação e de trabalho de professores(as) de enfermagem}

A professora A1 é casada, sem filhos, tem 37 anos. Graduou-se em enfermagem numa universidade pública federal no Sul do País, tendo concluído bacharelado e licenciatura. Especializou-se em Gestão da Saúde e em Saúde da Família pela mesma universidade. É mestranda em uma universidade particular na cidade em que trabalha. $\mathrm{Na}$ graduação realizou pesquisas de iniciação científica com bolsa do Conselho Nacional de Desenvolvimento Científico e Tecnológico (CNPq), na área de saúde da criança e da mulher. Seu primeiro emprego foi como professora substituta, na instituição na qual se formou, com contrato de trabalho de um ano. Trabalhou em central de materiais e centro cirúrgico e, concomitantemente, foi docente em escola técnica de enfermagem; ambos os cargos eram em instituições particulares. Foi enfermeira de vigilância epidemiológica concursada, período em que deixou o emprego no hospital. Em 2002, assumiu por concurso público a Estratégia Saúde da Família 


\section{pro.posıções}

$e$-ISSN 1980-6248

http://dx.doi.org/10.1590/1980-6248-2015-0155

(ESF), como coordenadora de uma Unidade Básica de Saúde, em que realizou programas de educação contínua com as equipes de saúde. Em seguida, pediu afastamento dos empregos no Brasil para acompanhar o marido em um trabalho na Itália. No período de quatro anos em que morou na Europa, foi voluntária hospitalar na assistência aos idosos com Alzheimer, já que não podia exercer a profissão lá. Em 2009, no Brasil, enviou currículos às escolas técnicas de enfermagem na região de Campinas, onde se estabeleceu. Na época da entrevista, atuava há dois anos como docente, coordenava o curso de formação de técnicos em enfermagem oferecido pelo governo estadual e sua jornada era de 40 horas semanais.

A professora A2 é solteira, sem filhos, tem 24 anos. Fez o ensino técnico em bioquímica, bacharelado e licenciatura em enfermagem em instituição pública estadual. Das entrevistadas é a mais nova. Trabalhou como técnica em bioquímica em um hospital público universitário. Quando ingressou na graduação em enfermagem, desistiu desse emprego, pois o curso era em período integral. Na graduação fez intercâmbio no Uruguai, e seu trabalho de conclusão de curso foi sobre cuidadoras de idosos. Após a graduação, seu primeiro emprego foi como docente na escola pesquisada. Depois de seis meses na docência, iniciou o trabalho como enfermeira em hospital privado no período da tarde. Seu contrato com a escola era de 25 horas semanais.

A professora A3 tem 35 anos, é casada e tem um filho. Fez graduação em enfermagem em instituição particular, foi bolsista com isenção da mensalidade. Estagiou na pediatria do hospital universitário. Fez licenciatura em faculdade privada. Iniciou, em instituição pública estadual, a especialização em unidade de terapia intensiva (UTI) neonatal e pediátrica, que foi interrompida pelo trabalho como coordenadora em uma unidade de UTI pediátrica por três anos. Concomitantemente, supervisionou estágios na área de puericultura na instituição na qual se formou. Depois da experiência na assistência hospitalar, foi convidada por um hospital privado para coordenar a educação continuada. Em 2004, iniciou a docência na escola pesquisada, mas foi interrompida, em 2008, pela gravidez e pelo casamento. Naquela época, o contrato de trabalho era temporário. Em 2010, foi contratada novamente pela escola, com carga horária de 40 horas semanais.

A professora A4 é solteira, sem filhos, tem 32 anos. Fez o curso de auxiliar de enfermagem durante o Ensino Médio. Conciliou a graduação em uma faculdade particular com o trabalho de auxiliar de enfermagem em um hospital. $\mathrm{Na}$ época da entrevista havia terminado 


\section{pro.posıções \\ $e$-ISSN 1980-6248}

http://dx.doi.org/10.1590/1980-6248-2015-0155

recentemente o curso de licenciatura em enfermagem numa instituição privada. Como enfermeira trabalhou em UTI de adulto em uma instituição privada. Nesse mesmo hospital exerce a docência no curso de técnico de enfermagem, juntamente com o trabalho na escola pesquisada. É especialista habilitada por instituições privadas em Central de Materiais e Centro Cirúrgico e Docência em Enfermagem. Seu contrato de trabalho era de 20 horas semanais.

O professor B1 é solteiro, sem filhos, tem 35 anos. Fez o curso de formação de professor nas séries iniciais; seu primeiro emprego foi como docente na Educação Infantil e Fundamental. Em decorrência do baixo salário como professor, foi comerciante. Concomitantemente ao trabalho no comércio, fez o curso de técnico em mobilizações ortopédicas. Durante seus estágios em hospitais, decidiu mudar de curso técnico e foi para a enfermagem. Fez o ensino técnico na escola em que atualmente leciona. Após o término do curso, ingressou em um hospital (pronto socorro) como auxiliar de enfermagem e conciliou esse trabalho com a graduação em faculdade privada. Em paralelo ao trabalho de enfermeiro, iniciou a docência em duas escolas de educação profissional em enfermagem. Realizou especialização educacional em enfermagem em instituição privada. Sua carga horária como docente na escola pesquisada era de 40 horas semanais. No período noturno leciona em outra escola técnica privada.

O professor B2 tem 37 anos, é casado e tem filhos. Graduou-se em matemática (licenciatura) e em enfermagem, ambas em faculdades privadas. Trabalhou na segurança pública antes de iniciar a graduação em enfermagem. Seu primeiro emprego como enfermeiro foi como docente em uma escola de educação profissional em enfermagem, no cargo de supervisor de estágios em um hospital público especialista em saúde da mulher. Depois de nove meses iniciou o trabalho como enfermeiro em hospital de médio porte. Em 2005, foi docente por seis meses na escola pesquisada e posteriormente saiu, devido ao contrato de trabalho ser temporário. Em 2010 retornou como docente, com vínculo empregatício de 40 horas semanais. É especialista em Saúde Pública em universidade pública estadual. Trabalhou como enfermeiro durante nove anos no sistema prisional no estado de São Paulo. 


\section{pro.posıções \\ $e$-ISSN 1980-6248 \\ http://dx.doi.org/10.1590/1980-6248-2015-0155 \\ As similitudes e as diferenciações entre ser professor e professora de enfermagem}

As idades dos entrevistados apontam para um grupo relativamente jovem, tendo a mais nova 24 anos e os mais velhos (A1 e B2), 37 anos na época da coleta de dados. Os salários são iguais para todos, variando apenas a carga horária para cada professor, como já dissemos anteriormente. Simultaneamente ao trabalho docente, somente A2 trabalha como enfermeira em um hospital privado. A4 e B1 realizam a docência em outras escolas particulares de ensino técnico.

Com relação às escolhas profissionais, as mulheres relatam o desejo de cursar alguma profissão na área da saúde. A escolha imediata pela enfermagem no vestibular se deu principalmente pelas professoras A1, A2 e A4. A professora A3 decidiu fazer enfermagem depois de pensar na possibilidade de medicina. De maneira geral, elas assumiram, desde o início, o trabalho de cuidar, seja como auxiliares ou enfermeiras. Os professores passaram pelas ciências exatas (B1) e pelo comércio (B2) antes de entrar para o cuidado em saúde. A trajetória no trabalho docente também é diferenciada: enquanto eles desenvolveram a docência em outras áreas, como matemática e ensino primário, elas tiveram a primeira experiência na educação continuada nos serviços de saúde (A3 e A4) ou nos cursos de licenciatura (A1 e A2). A escolha da profissão não deixa de ser uma construção social e, neste caso, as professoras entrevistadas expressam a condição feminina de cuidar do outro(a), ou seja, estão nas áreas consideradas de pouca qualificação e de baixos salários, como a enfermagem e a docência (Almeida, 2006).

Esses achados corroboram as pesquisas nas quais as mulheres estão nos guetos ditos “femininos", na área da educação, da saúde e de prestação de serviços, predominantemente (Bruschini \& Lombardi, 2002). As autoras mostram que, segundo os dados do Ministério da Educação (MEC), em 1997, 61\% dos concluintes do Ensino Superior eram mulheres e 67,6\% delas na área das ciências da saúde. A feminização da força de trabalho na saúde é corroborada pelo estudo de Machado, Vieira e Oliveira (2012), em que 70\% de toda a área é de mulheres, 90\% delas na enfermagem.

Já os enfermeiros entrevistados estiveram presentes nos locais nos quais a presença masculina é requisitada, como no pronto socorro (B1) e na segurança prisional, como no caso de B2: 


\section{pro.posições}

$e$-ISSN 1980-6248

http://dx.doi.org/10.1590/1980-6248-2015-0155

Em 2002, comecei a trajetória na saúde pública junto ao sistema prisional do estado de São Paulo, onde que eu ocupei um cargo até agora, em setembro deste ano, como diretor regional de saúde, responsável por 31 ambulatórios, participando de políticas públicas estaduais em saúde, públicas e, inclusive, nacionais, aonde a gente teve voz ativa junto ao Ministério da Saúde, em construção de políticas e modificações de políticas públicas junto ao sistema prisional, que a responsabilidade dele é a questão da AIDS. (B2)

Os postos de trabalho de enfermeiros são aqueles que requerem os atributos ditos masculinos, como força física e virilidade, por exemplo. A presença masculina na enfermagem está, sobretudo, nas áreas de psiquiatria, ortopedia e radiologia: "Essa tradição segue as características das práticas terapêuticas vinculadas ao uso da força física e baseadas na noção de risco técnico. Executar atos de contenção, tracionar, irradiar, são verbos conjugados nos processos de trabalho nesses setores" (Lopes \& Leal, 2005, p.120). Já as professoras entrevistadas estiveram no cuidado de saúde da família e no cuidado de gestantes e crianças, como expressam A1 e A3, respectivamente.

Consideramos que, à exceção de B2 (professor de Ensino Fundamental e Infantil), nenhum (a) desejou ser professor (a) antes de entrar para a enfermagem. Foi no convívio com hospitais e com os centros de saúde e, sobretudo, com o desenvolvimento de atividades de educação continuada que as professoras A3 e A4 desejaram seguir para a docência em enfermagem. Talvez por terem realizado inicialmente o bacharelado, não tiveram contato com os cursos de licenciatura e não vivenciaram a possibilidade de serem professoras ainda na graduação, como as professoras A1 e A2.

Salientamos que a escolha pelo segundo curso de graduação - a enfermagem -, para B2, foi em decorrência do trabalho de sua esposa:

A decisão foi motivada pela minha esposa, ela é... Quando nós nos conhecemos, ela estava terminando a faculdade dela, estava numa área da qual eu não tinha muita pretensão de permanência, que é a área de segurança, não é? E vi uma chance, uma forma de mudar a vida, ou seja, uma possibilidade, e aí teve um investimento nessa possibilidade. (B2)

O fato de ter alguém de sua convivência que é enfermeira pode corroborar a ideia de que é por meio das experiências entre os indivíduos na sociedade que os desejos e as vontades vão se construindo na medida das relações sociais (Elias, 1995). Embora tenha escolhido uma profissão majoritariamente feminina, permaneceu por um tempo longo como enfermeiro no setor prisional. 


\title{
pro.posições
}

$e$-ISSN 1980-6248

http://dx.doi.org/10.1590/1980-6248-2015-0155

A dimensão das representações sobre ser enfermeiro(a) é tida como desvalorizada em relação ao trabalho da medicina, como comenta A1, ao dizer a sua família da sua aprovação no vestibular em enfermagem:

\begin{abstract}
Quando eu passei no vestibular, dai meu nome saiu no listão e saiu como enfermagem, o pessoal diria: está errado. [Risos] E eu diria: não está errado. Ah, então, você passou em segunda op̧cão. Eu falei: não, passei na opção que eu escolbi. E por que você não nos contou? Porque existia uma pressão, não é? Uma pressão familiar para eu fažer medicina e tal, uma pressão do meu atual marido que, na época, a gente era namorado. Então, assim, tem... tinha uma pressão social, não é? Que enfermagem nunca foi um grande status, assim, quando a gente pensa; e aí, depois, conhecendo a faculdade, eu descobri que era... Estava tudo errado, não é? Que, na verdade, eu sempre quis mesmo era enfermagem, não é? E que essa pressão social era tudo uma questão de não conbecer a profissão, de não saber como... O que o enfermeiro faz, exatamente, porque a população tem uma visão um pouquinho distorcida, tinha... Acho que boje já melhorou um pouco mais, tinha uma visão muito distorcida da profissão e aí eu fui me apaixonando, então a graduação toda foi muito legal, não é? (A1)
\end{abstract}

As representações da família da professora A1 estariam relacionadas com o fato de o trabalho da mulher (enfermagem e cuidado) estar hierarquicamente inferior ao trabalho do homem (medicina e tratamento)? Nesse sentido, a divisão sexual do trabalho na área da saúde está posta, já que o trabalho médico é mais valorizado, com maior remuneração, além de que os saberes médicos, grosso modo, organizam o processo de trabalho em saúde, estabelecendo as relações de poder entre a medicina e a enfermagem (Lopes \& Leal, 2005). Embora haja o processo de feminização, a presença predominantemente masculina na medicina é evidenciada nos dados de Scheffer e Cassenote (2013), em que 60,09\% dos médicos eram homens no ano de 2010 .

Sendo assim, para a professora A1, houve a "pressão social" e a ideia de que "a enfermagem nunca foi um grande status". Corroborando esse questionamento, concordamos que

uma vez desvalorizado o trabalho que as mulheres realizam no âmbito doméstico e sendo o cuidar profissional, em muitos momentos, confundido com o que se dá nesse espaço, há uma estreita relação entre o lugar social de mulheres e enfermeiras... controlando e reduzindo a função da mulher à de mãe, esposa e educadora, sendo permitida a atuação no mundo público desde que somassem a obediência do marido e aos médicos. (Coelho, 2005, p. 346)

A história aponta que as enfermeiras foram influenciadas pela cultura e educação americana, que valorizava os atributos de docilidade, paciência, do instinto materno e da submissão ao trabalho médico. As escolas no início do século passado aceitavam apenas as 


\section{pro.posıções}

$e$-ISSN 1980-6248

http://dx.doi.org/10.1590/1980-6248-2015-0155

mulheres, contribuindo para a exclusão dos homens na profissão. No entanto, hoje a presença dos homens na profissão está cada vez mais crescente (Coelho, 2005).

Sob a perspectiva histórica, Renovato, Bagnato, Missio e Bassinello (2009) afirmam a influência do modelo de Florence Nightingale no ensino de enfermagem no Brasil. A profissão tida como vocação, e não como trabalho, foi um dos princípios da formação para o cuidado, sobretudo hospitalar. Ressaltamos ainda que o modelo Nigthingale tinha como preceito a enfermeira dócil, religiosa, imbuída de sentimentos modestos e delicados (Costa, Padilha, Amante, Costa, \& Bock, 2009), valores esses que foram sobremaneira requeridos no espaço produtivo hospitalar, ao longo da história da enfermagem (Lopes \& Leal, 2005). Somam-se a isso as influências do taylorismo nas atividades de enfermagem, confirmando a necessidade da execução de técnicas, de controle do tempo, disciplinarização das estudantes, hierarquização das atividades, além de que

o modelo vocacional se organiza ideologicamente em torno da prática de enfermagem como uma vocação, um chamado, um trabalho que vai requerer auto sacrifício. E se institucionaliza, através do disciplinamento, a fim de tornar possível o trabalho de auxiliar a prática médica. (Backes, 1999, p. 255)

As representações femininas na profissão também foram encontradas na pesquisa de Jesus et al. (2010), na qual a maioria dos entrevistados relatou manifestações de preconceito e estigmas na escolha da profissão: os familiares mais próximos colocaram a enfermagem como uma profissão inferior à medicina e um "imaginário feminino de submissão e inferioridade” (p. 169).

É comum, nas trajetórias, a conciliação do trabalho na assistência em enfermagem com o trabalho docente, tanto para os homens como para as mulheres:

fiz. tudo concomitante, ... trabalhava de manhã na universidade, à tarde no hospital e à noite na escola técnica. (A1)

Continuei levando os dois, ... trabalhava à noite no hospital e vinha pra [escola] outro dia de manhã e ai eu fazia 25 horas de manhã e à tarde eu ia pra casa descansar; até meio dia eu ficava aqui.... E à noite eu trabalho no hospital, mas dando aula na supervisão de estágio. (B1)

Nesse sentido, há pistas para pensarmos no trabalho docente de nível técnico como aquele relacionado ao baixo status e à baixa remuneração. Quando conciliavam a assistência de 


\section{pro.posıções}

$e$-ISSN 1980-6248

http://dx.doi.org/10.1590/1980-6248-2015-0155

enfermagem com a docência, os sujeitos relatam vínculo precário e flexível nos contratos de trabalho de professor. Se considerarmos a divisão sexual do trabalho, há de se pensar que as ocupações femininas, muitas vezes, são caracterizadas pelo rebaixamento salarial, por condições de trabalho precárias, pouco prestígio social, sobretudo na área de educação e da saúde (Vianna, 2013). Consideramos também a rápida expansão do ensino técnico em enfermagem nos últimos anos, principalmente pela iniciativa privada, caracterizada por uma formação minimalista e aligeirada (Bagnato, Bassinello, Lacaz, \& Missio, 2007). Com isso, as condições de trabalho dos professores se colocam como precárias e assim são expressas por todos os entrevistados, principalmente em empregos anteriores como docentes do ensino técnico.

Da mesma maneira, podemos pensar na conciliação entre os estudos durante a graduação e o trabalho desenvolvido por eles como auxiliares de enfermagem, como o caso da professora A4 e do professor B1. A professora A1 foi bolsista de iniciação à pesquisa, B2 trabalhou durante a graduação na segurança pública e A2 foi a única que desistiu do emprego para cursar a graduação em enfermagem.

No segundo ano de faculdade, ... tinha um projeto de bolsa, de bolsistas, onde alguns alunos eram pinçados, alunos com notas boas e que tinham interesse na bolsa, onde era uma bolsa de cem por cento, onde você trocava uma supervisão num determinado local pela sua bolsa. Passei no processo, fui uma das alunas escolbidas e, assim, como eu sempre me identifiquei muito com pediatria, sempre gostei muito, meu local, então, de supervisão seria a pediatria, então en ficava o dia todo na faculdade, sete horas da noite en pegava o plantão no bloco de pediatria e só saía às sete horas da manhã, que eu já emendava com a faculdade. (A3)

Olha, primeiro, não foi uma época fácil, não é? Porque trabalhar, eu fazia 12 horas durante o dia, dia sim e dia não, então, no outro dia, até que eu dava uma descansada, me dedicava aos estudos, mas tem dias que é, assim, você fica extremamente cansada, eu me lembro. Foi bom, foi ótimo, mas foi bem puxado, bem cansativo, não é? Mas, assim, eu acredito que, pra mim, foi bom, porque, ao mesmo tempo que eu estava trabalhando e vendo outras coisas, eu estava aprendendo mais, me dedicando mais, foi bom, por esse lado foi ótimo, foi excelente, assim, tem muitas coisas da prática que eu já fazia que eu estava vendo, isso foi ótimo, foi bom. (A4)

As duas professoras (A3 e A4) e o professor B1 relatam terem cursado a faculdade na iniciativa privada e terem conciliado com os estudos suas atividades, quer como bolsista, quer como auxiliar de enfermagem em hospitais privados, para manter e pagar o curso durante a graduação. Essa experiência é tida ora como portadora de benefícios (vivenciar a teoria e a prática ao mesmo tempo), ora como causa de cansaço e desgaste. Neste caso, há indícios de como a profissão se foi construindo nas condições de trabalho, geralmente precárias. Foi a 


\section{pro.posições}

$e$-ISSN 1980-6248

http://dx.doi.org/10.1590/1980-6248-2015-0155

conciliação do emprego de nível médio com os estudos que permitiu a A4 e B1 obter a graduação em enfermagem.

As trajetórias de trabalho e de formação diferenciam-se pela dinâmica das relações de gênero e de classe social. Considerando os depoimentos, B1 inicia os estudos para o ensino primário, já que na época o governo oferecia bolsa de incentivos (um salário mínimo) para a carreira de professor. A sua entrada no ensino primário foi em decorrência de apoio financeiro da prefeitura:

Eu acho que eu comecei... A cidade era... Ofereciam-me, onze anos atrás, era muito tempo, não é? Não me oferecia campo de trabalho, era a opção para os adolescentes, praticamente, não é? Os jovens da cidade, então a gente acabava optando por fazer o ensino bem melhorado, não é? Que era esse projeto do governo, e ainda ganhava pra isso, tinhas chances de sair trabalhando, então a gente tinha essa op̣̦ão em relação a isso. (B1)

Embora a docência tenha como característica a presença maciça das mulheres, os dados da rede municipal de São Paulo entre 2005 e 2010 mostram um aumento de 30\% de homens no quadro de educadores, professores, diretores e auxiliares de educação. No entanto, a pesquisa de 2009 do INEP/MEC revela que 64,1\% dos professores no Ensino Médio eram mulheres (Vianna, 2013). Ao que parece, para o professor B1, a entrada na docência esteve relacionada com uma oportunidade de obter um diploma e um salário para o estudo, corroborando a dimensão de classe social para a entrada na profissão docente.

Salientamos que as contradições entre o trabalho produtivo e o da maternidade são postas pela única professora que tem filhos. Ao se casar e engravidar, ela teve que romper com o trabalho de enfermeira e professora.

na verdade, depois de 2004, en fiquei grávida, que aí eu casei, fiquei grávida e dai eu parei, não é? ... Ai aqui eu vim [escola] com a proposta de quatro horas. E ai me convidaram a fazer oito horas e aí eu fiquei, assim, num impasse, não é? E agora? Eu vou pra oito? Não vou pra oito, não é? Porque o meu propósito, então, era quatro horas, pegar uma outra parte, estudar, não é? Dedicar a familia, tal, só que aí eu tive outros problemas pessoais, familiares, em casa, que me impulsionaram também a fazer oito horas e aí eu voltei pra oito horas; mas eu posso dizer pra você que é muito diferente uma coordenação hospitalar de hoje, uma docência, oito horas, não é? (A3)

Também para a professora A1, a trajetória de trabalho foi interrompida para poder acompanhar seu marido à Europa por motivo de transferência de emprego dele. 


\section{pro.posições}

$e$-ISSN 1980-6248

http://dx.doi.org/10.1590/1980-6248-2015-0155

Ai eu me exonerei da saúde da familia, pedi um afastamento sem remuneração, não é? No outro, porque a saúde da família era um concurso público, mas com direito celetista, então, a gente era celetista, tinha carteira assinada e direitos celetistas. $O$ outro não, o outro era estatutário. Ai eu me afastei e fui para a Itália. Ai fiquei um ano lá me descobrindo, não é? Tipo, ah, o que que eu vou fazer aqui, não é? Aquela coisa meio perdida, assim, aí, depois de um ano, eu entrei em um grupo que chamava "Associação dos voluntários" [no hospital]. (A1)

A saída das mulheres do mercado de trabalho para o cuidado com filhos pequenos e/ou para o casamento é uma realidade na nossa sociedade. Nesta pesquisa, a única professora com filhos interrompeu a trajetória para exercer o cuidado familiar. Um estudo europeu sobre mulheres, maternidade e trabalho corrobora a ideia de que políticas sociais e familiares são necessárias para que elas não precisem escolher entre trabalhar ou cuidar de filhos, para que o trabalho na esfera produtiva possa ser conciliado com a reprodução e vice-versa:

Permanecer no mercado de trabalho é crucial para sua independência feminina, para o desenvolvimento da sociedade e, talvez, até para a sobrevivência dos sistemas de proteção social. Pois o nascimento de um filho pode obrigá-las a interromper sua atividade profissional, forçálas a trabalhar em tempo parcial, levá-las a mudar de emprego ou de setor de atividade, e essas diferentes mudanças são acompanhadas de perdas de rendimentos e de menores perspectivas de carreira. (Meuderls, Plasman, Henau, Maron, \& Dorchay, 2007, p. 612)

Para as entrevistadas, há diferenças entre o trabalho docente e o exercício das atividades de educação continuada realizada em hospitais. A professora A3 pondera que o trabalho docente extrapola o horário em sala de aula e aponta as exigências para além do "dar aula", o tempo gasto com a preparação dos conteúdos, correções de provas e elaboração de materiais didáticos:

Eu tinha em mente que era apenas o meu trabalho aqui, eram oito horas apenas diárias dentro da escola, mas não é, você leva para casa, porque você leva trabalho, você leva prova, você vai elaborar aula, você vai planejar, você vai elaborar uma atividade, não é? ... E aí, assim, era madrugada sem dormir, porque aí eu ficava me preparando, estudando, montando aula. (A3)

Importa considerar as atividades realizadas por essa professora no espaço doméstico e familiar, pois a extensão da docência é levada para casa. A intensidade do trabalho docente está relacionada com o tempo exercido no contato com os estudantes e suas relações afetivas, no cumprimento das exigências da legislação, na preparação de aulas, de avaliações e em correções. Há também o tempo despendido em reuniões pedagógicas, formação contínua e fora do espaço escolar, nas tarefas domésticas e familiares, para grande parte dos professores (Tardif \& Lessard, 2005). Da mesma maneira, as professoras entrevistadas no estudo de Zibetti e Pereira (2010) 


\section{pro.posições}

$e$-ISSN 1980-6248

http://dx.doi.org/10.1590/1980-6248-2015-0155

também revelaram o uso do tempo livre com atividades da escola, como planejamento e preparação de aulas.

Embora tenha como centralidade o cuidado no trabalho de enfermagem, ele também é pertencente à docência. Nas relações sociais entre professor(a) e estudante, o cuidado integra o ato educativo. Tanto as professoras quanto os professores despendem atenção, solicitude e preocupação com a aprendizagem, com as reflexões, os questionamentos e os problemas dos alunos:

eles veem realmente, se você der abertura, eles te veem como uma pessoa para aconselhar, então eles vêm perguntar: nossa, você acha que eu vou dar conta, você acha que eu vou conseguir trabalhar com esse tipo de população? E, assim, a gente acaba, eu acabo tendo bastante oportunidade de conversar sobre isso, principalmente quando eu estava no [curso], dando saúde mental, que é uma área que todo mundo tem alguém na família, todo mundo conhece alguém, todo mundo tem um histórico na saúde mental, e é um assunto muito delicado, não é? Então, nossa, eles vinham bastante comentar, questionar o próprio preparo profissional, não é? Então, assim, sempre tentei conversar com os alunos sobre isso, não é? Propor uma reflexão, para eles verem se eles estão seguindo ali o que eles desejam mesmo, se estão cientes da área que eles estão seguindo. (A2)

Também eles tinham... Às vezes, vinham de pós-plantão, às vezes não dava pra vir, não é? Às vezes vinham pra dormir na sala, então houve um pequeno problema em relação a isso, não é? Às vezes, as alunas que já tinham netos traziam os netos pra cuidar dentro da sala de aula, ai a gente tinha esse impasse, não é? É proibido... como é que a gente vai proibir, ela vai embora, então esse foi um grande problema em relação a isso, às vezes, as mães traziam os filhos, não tinham com quem deixar pra cuidar, esse foi um dos grandes impasses em relação a isso. (B1)

O professor B1 mostra a dificuldade de suas alunas, estudantes e trabalhadoras de enfermagem, para conciliar o trabalho produtivo (plantões em hospitais e ensino técnico) e o da esfera da reprodução (cuidado com os filhos e/ou netos), pois "as esferas produtiva e reprodutiva se interpenetram, se entrecruzam, na definição da situação (tempo, espaço, qualidades) do trabalho feminino" (Lopes \& Leal, 2005, p.112).

O cuidado, entendido como aquele que despende atenção, responsabilidade, solicitudes, paciência, interações e emoções (Soares, 2012) com os estudantes, é posto tanto pelos professores quanto pelas professoras. Para todos os entrevistados o cuidado com o aluno é integrante do ato educativo e do processo de ensino e aprendizagem. E, quando percebem que atingiram a finalidade da educação, ou seja, quando os veem como profissionais no mercado de trabalho, com ética e sabendo fazer o cuidado, é motivo de contentamento e orgulho. Se a intenção é a de desenvolver a "prática pedagógica criativa e dialógica contribuindo com a 


\section{pro.posıções \\ $e$-ISSN 1980-6248}

http://dx.doi.org/10.1590/1980-6248-2015-0155

formação de sujeitos críticos e reflexivos” (Canever, Prado, Backes, \& Gomes, 2012, p. 217), todos a conseguem por meio do trabalho educativo.

E consigo também, ali, ir despertando naquele aluno qual era a visão ética dele na postura da decisão que ele iria tomar, por quê? Porque gerava nele uma certa inquietação, era isso que a gente, nós, professores, sempre tentamos fazer. (B2)

Foi comum para os(as) depoentes que as dificuldades iniciais se relacionassem ao convívio com os estudantes e à preocupação com o "ensinar bem”: despertar a consciência ética; entender o sistema de saúde; mostrar as técnicas e os procedimentos de enfermagem e as políticas de saúde. Tanto para os professores quanto para as professoras, o fato de os estudantes já serem profissionais da área (auxiliares de enfermagem) trouxe receio e ansiedade. Para todos os entrevistados, à medida que foram convivendo e "trocando" experiências com os estudantes, se sentiram mais seguros e entenderam que houve evolução no processo de ensino e de aprendizagem.

Durante o processo de construção de ser professor ou professora de enfermagem, todos alegam que a ajuda de colegas mais antigos foi importante para que pudessem aprender a dar aula. Embora a professora A2 tenha realizado o curso de licenciatura, verbaliza que ele não foi suficiente para o início do trabalho. O fato de não ter tido experiência como enfermeira a princípio trouxe apreensão, mas, com o tempo, ela foi percebendo o quanto a sua formação acadêmica e teórica poderia contribuir para o ensino técnico. Assim, os saberes experienciais vão ocorrendo ao longo do processo educativo na dinâmica do cotidiano (Tardif, 2005).

Como já dito anteriormente, somente duas professoras realizaram o curso de licenciatura concomitante ao bacharelado, ambas em universidades públicas. Apesar do aumento de enfermeiros docentes atuando nos cursos de formação técnica em enfermagem nos últimos anos, é evidenciada a formação hospitalar/curativa e com pouca ênfase na preparação para exercer a docência, ainda que as Diretrizes Curriculares Nacionais sinalizem a formação pedagógica dos enfermeiros (Sgarbi, Marques, Calças, \& Missio, 2015, p.56). Com isso, concordamos que a licenciatura em enfermagem é "uma questão não resolvida, com diferentes encaminhamentos, mas que têm buscado garantir que a licenciatura da área não se dê desarticulada da formação inicial, sendo que esta foi a principal preocupação durante todo o processo de discussão desta temática” (Bagnato \& Rodrigues, 2007, p. 511). 


\section{pro.posıções}

\section{$e$-ISSN 1980-6248}

http://dx.doi.org/10.1590/1980-6248-2015-0155

Para a professora A2, o curso de licenciatura não foi suficiente para conseguir desenvolver seu trabalho inicial:

Você tem que se adaptar com toda uma rotina de fazer um planejamento de aula, preparar aula, os métodos de avaliação, então tudo isso não é fácil, não é? A gente não sai tão preparado assim da licenciatura, então, no começo, é um pouco difícil, assim, sabe? Ver os dois primeiros meses até você se adaptar, ver o que funciona e o que não funciona, não é? Mas depois você vai pegando o jeito. (A2)

O que enfatizamos é: de que maneira os cursos de licenciatura estão preparando os(as) enfermeiros(as) para desenvolver a docência? A formação de professores do ensino técnico em saúde é uma preocupação das políticas ministeriais (Mathias \& Algebaile, 2011). Consideramos, pois, que a formação para a docência de nível técnico em saúde deve ser uma das centralidades das políticas de educação profissional. Segundo a regulamentação das Diretrizes Curriculares da Graduação em Enfermagem do Conselho Nacional de Educação, o professor que atuar no ensino técnico deverá ter a licenciatura plena para o exercício docente (Sgarbi et al., 2015).

Entretanto, dois enfoques merecem destaque. O primeiro é a desvalorização desses professores, seja pelas condições salariais, seja pelo status social. O outro está relacionado ao grande contingente de professores que não possuem o Ensino Superior na área de docência. Kuenzer (2011), apoiada nos dados do INEP de 2009, relata que houve avanço no cumprimento das determinações da LDB 9394/96, acerca da formação de professores do Ensino Médio: 91\% têm curso de nível superior e $87 \%$ possuem licenciatura. O dado preocupante é que 53\% dos professores não atuam na sua área de formação: “a política de formação só tem sentido quando integrada à estruturação da carreira docente, à política salarial que assegure a dignidade do professor e à garantia de condições adequadas de trabalho" (p. 672).

O aligeiramento da formação docente, sem aprofundamento dos fundamentos das Ciências da Educação, o caráter pragmatista, a diminuição da carga horária da formação específica e o aumento dos cursos a distância (Bagnato et al., 2007), são aspectos relevantes. Há de se pensar a formação para além das práticas pedagógicas, como a melhoria das condições de trabalho, a ênfase nos contratos de trabalho formais e/ou estáveis e as melhorias nas condições de trabalho e remuneração.

$\mathrm{Na}$ interação com os alunos e com outros docentes, o professor deve ser capaz de lidar com adversidades, tais como insegurança e medo. Tais sentimentos são, nesta pesquisa, 


\section{pro.posições}

$e$-ISSN 1980-6248

http://dx.doi.org/10.1590/1980-6248-2015-0155

comumente vividos por homens e mulheres. A atenção e o cuidado com os estudantes são marcas do fazer a educação: preocupar-se com os estudantes faltosos, com o processo de ensino e aprendizagem, com o ensino do cuidado na perspectiva ética marca as trajetórias dos entrevistados. Portanto, o trabalho docente é portador de prazeres e contentamentos, ao "despertar" nos estudantes a importância do pensar e do fazer saúde. O reconhecimento no trabalho é posto por todos:

Nossa, para mim, o melhor orgulho foi, quando eu estava agora em novembro, em estágio na maternidade, eu encontrei uma aluna, que foi minha aluna, que se formou em julho e estava trabalhando na maternidade. Gente, ela veio toda feliz. me agradecer, não pode ter realização maior que essa, que você vê uma pessoa que você ajudou a fazer uma formação e que está lá está trabalhando e tal. Sendo reconhecida pelo seu trabalho, é para isso o seu trabalho. Para você depois olhar para os seus alunos e ver que ajudou a fazer uma formação de qualidade. Isso porque eu acredito que [a escola] dá uma formação de qualidade, não é? (A2)

Porque você é uma referência para aquelas pessoas, então eu acho que, sem dúvida nenhuma, é uma parte muito especial de ser docente, poder trabalhar com curso técnico. A graduação é muito bom também; na graduação, o aluno da graduação, ele tem outra autoestima, ele está em outro patamar social. Mesmo que ele esteja na mesma classe social do nosso aluno do técnico, não é? Mas ele é socialmente visto de uma outra maneira. (A1)

As ligações afetivas que professores e professoras construíram com os estudantes são integrantes do reconhecimento no trabalho. Se o cuidado é portador de emoções e afetos (Soares, 2012), no caso desses docentes o ato educativo também o é. Para todos, vivenciar os estudantes galgando o conhecimento e sendo éticos e pertencentes ao sistema de saúde no Brasil é motivo de satisfação e contentamento: "Foi, é muito satisfatório, muito, então eu não... Eu não sabia que a docência pra mim seria isso, pra mim, hoje em dia, é fundamental, então, eu não troco, gosto muito” (B1).

\section{Conclusões}

Ao questionar as trajetórias de professores(as) do ensino em enfermagem, verificamos que essas são construídas, em alguns momentos, pelas diferenciações entre ser homem e ser mulher. A ruptura com a carreira é a experiência de uma delas, ao engravidar e casar, o que não ocorreu com o professor que tem filhos. A trajetória profissional foi interrompida na vida da professora A1, que acompanhou o marido à Europa por motivo de trabalho dele. Neste aspecto, as relações de gênero e a divisão sexual do trabalho foram fundamentais para compreender as diferenças entre ser professor e ser professora de enfermagem. As imbricações 


\section{pro.posições \\ $e$-ISSN 1980-6248}

http://dx.doi.org/10.1590/1980-6248-2015-0155

familiares e do cuidado com filhos foram motivos de interrupção do trabalho delas, aspectos encontrados em diversos estudos que tomam como análise a divisão sexual do trabalho.

As escolhas da profissão também se colocam como diferenciadas por eles: as mulheres decidiram pela carreira de enfermagem, embora uma delas tenha se interessado pela medicina, a priori, porém os professores iniciaram a carreira como docentes na área de ciências exatas (matemática) e no ensino primário e fundamental. Os caminhos percorridos por eles na enfermagem passam pelo cuidado no sistema prisional e em pronto socorro, já as professoras atuaram na saúde da família, no cuidado de gestantes e crianças.

Entretanto, a similitude no trabalho deles reside no ato educativo, pois ambos se preocupam com a qualidade do processo de ensino e aprendizagem. Fazem da educação um espaço de cuidado com o outro. Se partimos do pressuposto que o cuidado é a essência do trabalho de enfermagem, a educação em enfermagem, para os sujeitos, tem como finalidade o despertar de um fazer saúde com qualidade e um processo reflexivo.

Esta pesquisa com o enfoque das relações de gênero e da história oral foi importante para desvendar as trajetórias e compreender como professoras e professores do ensino técnico de enfermagem constroem os seus trabalhos. Entretanto, a pouca produção científica sobre a temática aqui abordada na área da enfermagem não permitiu comparações e aproximações com outros estudos.

Sugerimos o aprofundamento de pesquisas que possam contribuir para o entendimento de como homens e mulheres se constituem docentes e quais suas implicações nas diferenciações de gênero. Por outro lado, as imbricações entre o trabalho na esfera produtiva e reprodutiva são indagações para futuras pesquisas: de que maneira enfermeiros (as) articulam o trabalho de cuidar e educar nas múltiplas jornadas de trabalho? Como constroem a carreira docente? 


\section{pro.posıções \\ $e$-ISSN 1980-6248}

http://dx.doi.org/10.1590/1980-6248-2015-0155

\section{Referências}

Almeida, J. S. (2006). Mulheres na educação: missão, vocação e destino? A feminização do magistério ao longo do século XX. In D. Saviani, J. S. Almeida, R. F. Souza, \& V. T. Valdemarin, O legado educacional do século XX no Brasil (pp.58-107). Campinas: Autores Associados.

Andrade, C. B. (2015). O trabalho de cuidar e educar: gênero, saber e poder (197pp.). Curitiba: Appris.

Backes, V. M. S. (1999). O legado histórico do modelo Nightingale: seu estilo de pensamento e sua práxis. Revista Brasileira de Enfermagem (REBEn), 52(2), 251-264.

Bagnato, M. H. S., Bassinello, G. A. H., Lacaz, C. P. da C., \& Missio, L. (2007). Ensino médio e educação profissionalizante em enfermagem: algumas reflexões. Revista da Escola de Enfermagem da USP, 41(2), 279-286.

Bagnato, M. H. S., \& Rodrigues, R.M. (2007). Diretrizes curriculares da Graduação de enfermagem: pensando contextos, mudanças e perspectivas. Revista Brasileira de Enfermagem (REBEn), 60(5), 507-512.

Bassinello, G. H. (2007). Projeto Larga Escala: análise histórica e compreensão dos resultados no Estado de São Paulo. Tese de Doutorado, Faculdade de Educação, Universidade Estadual de Campinas, Campinas, 2007.

Bruschini, M. C., \& Amado, T. (1998). Estudos sobre mulher e educação: algumas questões sobre o magistério. Cadernos de Pesquisa, 64(1), 4-13.

Bruschini, M. C., \& Lombardi, M. R. (2002). Instruídas e trabalhadeiras: trabalho feminino no final do século XX. Cadernos Pagu, 17(18), 157-196.

Canever, B. P., Prado, M. L., Backes, V. M. S., \& Gomes, D. C. (2012). Produção do conhecimento acerca da formação do enfermeiro na América Latina. Revista Gaúcha de Enfermagem, 33(4), 212-220.

Coelho, E. A. C. (2005). Gênero, saúde e enfermagem. Revista Brasileira de Enfermagem, 58(3), 345-348.

Costa, R., Padilha, M. I., Amante, L. N., Costa, E., \& Bock, L. F. (2009). O legado de Florence Nightingale: uma viagem no Tempo. Texto \& Contexto Enfermagem, 18(40), 661-669. 


\section{pro.posıções \\ $e$-ISSN 1980-6248}

http://dx.doi.org/10.1590/1980-6248-2015-0155

Demartini, Z. F. D. (1999). Trabalhando com relatos orais: reflexões a partir de uma trajetória de pesquisa. In A. B. S. G. Lang (Org.), Textos CERU (pp. 33-46). São Paulo.

Elias, N. (1995). Mozart: sociologia de um gênio. Rio de Janeiro: Zahar.

Gama, A. S. (2014). Trabalho, familia e gênero: impactos dos direitos do trabalho e da educação infantil. São Paulo: Cortez.

Hirata, H., \& Kergoat, D. (2009). Paradigmas sociológicos revistos à luz da categoria de gênero. Que renovação aporta a epistemologia do trabalho? Novos Cadernos NAEA, 11(1), 3950.

Jesus, E. S., Marques, L. R., Assis, L. C. F., Alves, T. B., Freitas, G. F. de, \& Oguisso, T. (2010). Preconceito na enfermagem: percepção de enfermeiros formados em diferentes décadas. Revista da Escola de Enfermagem da USP, 44(1), 166-173.

Joutard, P. (2000). Desafios à história oral do século XXI. In M. Ferreira, T. Fernandes, \& V. Alberti, História oral: desafios para o século XXI (pp.31-46). Rio de Janeiro: Editora Fiocruz; FGV.

Kergoat, D. (1986). Em defesa de uma sociologia das relações sociais: da análise crítica das categorias dominantes à elaboração de uma nova conceituação. In A. KartchvskyBulport et al., O sexo do trabalho (pp.79-93). Rio de Janeiro: Paz e Terra.

Kuenzer, A. (2011). A formação de professores para o ensino médio: velhos problemas, novos desafios. Educação e Sociedade, 32(116), 667-688.

Lopes, M. J., \& Leal, S. M. (2005). A feminização persistente na qualificação profissional da enfermagem brasileira. Cadernos Pagu, 24(1), 105-125.

Machado, M. H., Vieira, A. L. S., \& Oliveira, E. (2012). Construindo o perfil da enfermagem. Enfermagem em Foco, 3(3), 119-122.

Mathias, M., \& Algebaile, J. (2011). Educação profissional em saúde no centro do debate. Revista RET-SUS, 5(44),10-21.

Meulders, D. et al. (2007). Trabalho e maternidade na Europa, condições de trabalho e políticas públicas. Cadernos de Pesquisa, 7(132), 611-640. 


\section{pro.posıções \\ $e$-ISSN 1980-6248}

http://dx.doi.org/10.1590/1980-6248-2015-0155

Padilha, M. I. C. S., Vaghetti, H. H., \& Brodersen, G. (2006). Gênero e enfermagem: uma análise reflexiva. Revista Enfermagem UERJ, 14(2), 292-300.

Pereira, I., \& Ramos, M. N. (2006). Educaşão profissional em saúde. Rio de Janeiro: Editora Fiocruz.

Renovato, R. D., Bagnato, M. H. S., Missio, L., \& Bassinello, G. A. H. (2009). As identidades dos enfermeiros em cenários de mudanças curriculares no ensino da enfermagem. Trabalho, Educação e Saúde, 7(2), 231-248.

São Paulo (Estado). (2009). Fundação do Desenvolvimento Administrativo. Relatório de Atividades. São Paulo.

Scheffer, M. C., \& Cassenote, A. J. F. (2013). A feminização da medicina no Brasil. Revista Bioética, 21(3), 268-277.

Segnini, L. P. R. (2014). Os músicos e seu trabalho. Tempo Social, 26(1), 75-86.

Sgarbi, A. K. G., Marques, M. P. S., Calças, I. R. R., \& Missio, L. (2015). Formação do enfermeiro para a docência no ensino técnico em enfermagem. Interfaces da Educação, 6(17), 44-65.

Soares, A. (2012). As emoções do care. In H. Hirata, \& N. A. Guimarães, Cuidados e cuidadoras: as várias faces do trabalho do care (pp. 44-60). São Paulo: Atlas.

Tardif, M. (2005). Saberes docentes e formação profissional. Petrópolis: Vozes.

Tardif, M., \& Lessard, C. (2005). O trabalho docente: elementos para uma teoria da docência como profissão de interações humanas. Petrópolis: Vozes.

Vianna, C. P. (2013). A feminização do magistério na educação básica e os desafios para a prática e a identidade coletiva docente. In S. C. Yannoulas (Org.), Trabalhadoras: análise da feminização das profissões e ocupações (pp.159-180). Brasília: Abaré.

Waldow, V. R. (2009). Reflexões sobre educação em enfermagem: ênfase em um ensino centrado no cuidado. Mundo Saúde, 33(2), 182-188. 


\section{pro.posıções \\ $e$-ISSN 1980-6248}

http://dx.doi.org/10.1590/1980-6248-2015-0155

Zibetti, M. L. T., \& Pereira, S. R. (2010). Mulheres e professoras: repercussões da dupla jornada nas condições de vida e no trabalho docente. Educar em Revista, n. esp., 259-276.

Submetido à avaliação em 17 de novembro de 2015; revisado em 31 de agosto de 2016; aceito para publicação em 03 de abril de 2017. 